\title{
Early Start Hemodialysis With A Catheter is Associated With Greater Mortality: A Propensity Score Analysis
}

\section{Gustavo Laham ( $\sim$ guslaham@yahoo.com.ar)}

Centro de Educación médica e investigaciones clínicas (CEMIC)

Gervasio Soler Pujol

Centro de Educación médica e investigaciones clínicas (CEMIC)

Jenny Guzman

Centro de Educación médica e investigaciones clínicas (CEMIC)

Natalia Boccia

Centro de Educación médica e investigaciones clínicas (CEMIC)

Anabel Abib

Centro de Educación médica e investigaciones clínicas (CEMIC)

Carlos H. Diaz

Centro de Educación médica e investigaciones clínicas (CEMIC)

\section{Research Article}

Keywords: End-stage kidney disease, hemodialysis, estimated glomerular filtration rate, vascular access, propensity score, mortality.

Posted Date: September 24th, 2021

DOI: https://doi.org/10.21203/rs.3.rs-669320/v1

License: (c) (i) This work is licensed under a Creative Commons Attribution 4.0 International License. Read Full License 


\section{Abstract}

Introduction: Deciding when and how to initiate hemodialysis (HD) is still controversial. An early start (ES) seems to show a lack of benefit. "Lead time bias" and comorbidities have been associated with different outcomes in ES groups. On the other hand, it is well accepted the impact that the type of vascular access (VA) has on patient survival. Our aim was to evaluate survival with early start (ES) vs. late start (LS) on HD, taking into account the vascular access (VA) used.

Methods: Between 01/95 and 06/18, 503 incidental patients initiated HD at our Dialysis Unit. eGFR was estimated by the CKDEPI equation. Diabetes mellitus (DM), coronary disease (CD), and peripheral vascular disease (PVD) were considered comorbid conditions. According to eGFR and VA, patients were divided into four groups: G1: ES (eGFR $>7 \mathrm{ml} / \mathrm{min}$ ) with catheter $(E S+C), G 2$ : ES with fistula or graft $(F / G)(E S+F / G), G 3$ : LS (eGFR< $7 \mathrm{ml} / \mathrm{min}$ ) with catheter $(L S+C)$, and G4: $L S$ with F/G $(\mathrm{LS}+\mathrm{F} / \mathrm{G})$. The cut-off value to define ES or LS was based on median eGFR for these 503 patients. We compared patient's survival rates by Kaplan-Meier and log-rank test. The four groups were compared before and after matching with propensity scores (PS). Cox analysis was performed to determine the impact of predictors of mortality.

Results: Median eGFR was 7 (5.3-9.5) $\mathrm{ml} / \mathrm{min} / 1.73 \mathrm{~m} 2$, median follow-up time was 30.9 (13-50) months, $52.1 \%$ had F/G access at entry, and $46.9 \%$ died during the observation period. Among the four groups, the $\mathrm{ES}+\mathrm{C}$ were significantly older, there were more diabetics and co-morbid conditions, while phosphatemia, iPTH, albumin, and hemoglobin were significantly higher in the LS groups. Before propensity score (PS) matching, the $E S+C$ group had a poor survival rate $(P<0.0001)$, while $L S+F / G$ access had the best survival. After PS, a total of 180 patients were selected in the same four groups and ES $+C$ kept showing a statistically significant poorer survival. Multivariate analysis revealed that ES+C was an independent predictor of mortality.

Conclusion: In this retrospective study, ES+C on HD was associated with a higher mortality rate than LS. This association persisted after PS matching.

\section{Introduction}

Chronic kidney disease (CKD) is one of the main public health problems worldwide. The amount of patients with end-stage renal disease (ESRD) requiring dialysis is increasing around the world [1]. Our country, Argentina, is not an exception. In 2020 there are 30500 prevalent patients on dialysis with an incidence and a prevalence of 160 and 673 patients per million inhabitants, respectively [2]. The mortality rate for patients with CKD stage $5 \mathrm{D}$ is $17.3 \%$, being $14.7 \%$ for peritoneal dialysis and $17.7 \%$ for hemodialysis patients [2]. It is well known that the rate of admissions in the first 3 months after initiating dialysis is high. [3]. Inadequate clinical and psychological patients' preparation before commencing dialysis has been mention as one of the main reasons for this bad outcome. Behind this problem, from the nephrologist's side, the correct Timing to initiate dialysis is poorly understood [4].

Today, adequate dialysis therapy can prevent uremic complications reduce mortality in this group of patients [5-6]. Therefore, the Timing to initiate dialysis matters in terms of complications and survival [7]. But deciding when and how to initiate dialysis is still controversial today. Initially, some studies associated an early start (ES) on dialysis with nutritional status improvement, better clearance of uremic toxins and survival, especially in ESRD patients with high comorbidities [8]. More recent studies fail to show such a benefit mainly attributed to "Lead time bias" and that comorbidities have been associated with bad outcomes in ES groups. Moreover, results differ depending on the GFR measurement used. In observational studies, higher eGFR at dialysis initiation has been associated with higher mortality risk, independent of nutritional status [9-10]. In contrast, studies that have employed timed urea or creatinine clearances rather than serum creatinine-based estimating equations to measure GFR have suggested that higher GFR at dialysis initiation may be associated with a lower risk for poor outcomes [11-13].

To date, there is only one randomized, prospective and controlled study (The Initiating Dialysis Early and Late trial, IDEAL study) reporting that, compared with a strategy of delayed dialysis initiation, earlier initiation in patients with advanced CKD was not associated with improved survival or quality of life, but was associated with increased costs [14]. 
Recent studies have used modern statistical techniques to try to minimize selection bias and other confounding factors. Using propensity score-matching, some studies have evaluated the effect of dialysis initiation timing on clinical outcomes. Crews DC et al. using data from the USRDS and incorporating numerous pre-dialysis clinical factors, compared early (eGFR of $>10$ $\mathrm{ml} / \mathrm{min} 1.73 \mathrm{~m} 2)$ versus late (eGFR $<10 \mathrm{ml} / \mathrm{min} 1.73 \mathrm{~m} 2$ ) dialysis initiation and their association with mortality and hospitalization risk. They found that in the propensity-matched cohorts' early initiation was associated with $11 \%$ of increased risk of all-cause mortality and $3 \%$ of hospitalization [15]. In another study, Lee $\mathrm{J}$ et al. found higher mortality for early initiation which disappeared after PS matching [7]. There is growing evidence that late nephrological referral of ESRD patients is associated with an increase morbi-mortality compared with early referral. Current data suggest that between 20 and $57 \%$ of patients in Europe and the US are not referred to the nephrologist on time [16-17]. One of the possible reasons for these results is that early referral patients are initiated on dialysis with functioning vascular access fashioned months before, after careful planning [18]. At the same time, in incident hemodialysis (HD) patients the use of catheters, whether tunneled or not, is related with a worse prognosis when compared to an arteriovenous fistula (AVF) [18]. Catheters are associated with an increased death rate from any cause in incident HD patients. This increased mortality was observed during dialysis initiation and after long-term follow-up [19]. The Argentine dialysis register shows that in our country $95 \%$ of patients initiate hemodialysis as renal replacement therapy and $73.8 \%$ of them do so with a catheter [2]. To date, there are no studies evaluating how these two variables, dialysis initiation timing and vascular access used, impact outcomes simultaneously. Our aim was to correlate patients' survival according to Early start vs. late start (LS) on HD, taking into account(considering) the VA used, pre and after a PS matching analysis.

\section{Methods}

\section{Study design}

In this retrospective, single-center, observational study, we evaluated 503 incidental adult ( $>18$ years old) patients that initiated HD in our Dialysis Unit at CEMIC between 01/1995 and 06/2018. Patients with kidney transplant failure, patients already on dialysis referred from other dialysis units (non-incident), or those who initiated peritoneal dialysis were excluded from the study. eGFR was estimated by the CKD-Epidemiology Collaboration (CKD-EPI) equation. [20]. We recorded the vascular access at entry as a catheter (transient o permanent) or Fistula/graft (F/G). We also recorded laboratory parameters before initiation of dialysis: hemoglobin ( $\mathrm{Hb}$ ), albumin (alb), urea, calcium (Ca), phosphorus $(\mathrm{P})$, and intact parathormone (iPTH)). Patients were divided in four groups according to eGFR and the type of vascular access at entry: G1: ES (eGFR $>7 \mathrm{ml} / \mathrm{min}$ ) with catheter (C) access (ES + C), G2: ES (eGFR $>7 \mathrm{ml} / \mathrm{min}$ ) with F/G access (ES + F/G), G3: LS (eGFR $<7 / \mathrm{min})$ with C access (LS + C), and G4: LS (eGFR $<7 / \mathrm{min}$ ) with F/G access (LS +F/G). The cut-off value to define ES or LS was based on median eGFR for the whole cohort of 503 patients. Diabetes mellitus (DM), coronary disease (CD) and peripheral vascular disease (PVD) were considered co-morbid conditions. Patient's survival was censored at the time of transplantation, end of the observation period (June 2020), or loss of follow-up. The primary outcome was all-cause mortality after dialysis beginning.

\section{Statistical Analysis}

Continuous variables were expressed as mean, median and standard deviation or interquartile range as appropriate. Frequencies and percentages were used for categorical variables. We applied t-test or Mann-Whitney to compared continuous variables and 1-way ANOVA when there were more than three groups. Chi-square test was used to compared categorical variables.

We calculated and compared patient's survival rates by Kaplan-Meier curve and log-rank test. To determine the impact of possible predictors of mortality a Cox proportional hazards analysis was performed. P-value $<0.05$ was considered statistically significant.

Comparisons were performed before and after propensity score matching. We calculated propensity scores from the logistic regression models which represented the probability of being assigned to either an early or late dialysis initiation group. We matched propensity scores one by one using nearest neighbor methods, no replacement, and 0.01 caliper width. Through the 
matching procedure, the early- and late-start groups demonstrated similar distributions of propensity scores, indicating that the differences in covariates between the two groups were minimized. IBM SPSS software (version 25.0) was used in all descriptive and survival analyses, and R software was used in the propensity score matching

\section{Results}

\section{Patients Characteristics}

A total of 503 patients that started HD in our Dialysis Unit entered the analysis. Mean age was $61 \pm 17$ years, $61.3 \%$ were male, $24.7 \%$ were diabetics, 38.7 and $13.4 \%$ had CD and PVD, respectively. Only $52.1 \%$ commenced HD with a F/G, the median eGFR was 7 (5.3-9-5) $\mathrm{ml} / \mathrm{min} / 1.73 \mathrm{~m} 2$. Reported laboratory values before the first dialysis session were: urea $189 \pm 64$ $\mathrm{mg} / \mathrm{dl}, \mathrm{Hb} 9.7 \pm 1.9 \mathrm{~g} / \mathrm{dl}$, alb $3.7 \pm 0.5$, Ca $8.7 \pm 3.7 \mathrm{mg} / \mathrm{dl}, \mathrm{P} 5.9 \pm 2 \mathrm{mg} / \mathrm{dl}$, iPTH 311 (154-541). The median follow-up time was 30.9 (13-50) months. Table 1. After dividing the whole cohort in for 4 groups according to eGFR and vascular access, 127 (25.2 \%) patients belonged to ES + C group: eGFR (9.7 ml/min), 127 (25.2 \%) to ES + F/G: eGFR (10.2 ml/min), $113(22.5$ $\%)$ to LS + C: eGFR (5.4 ml/min) and $136(27 \%)$ to LS + F/G: eGFR (5.2 ml/min). Patients in the ES + C group were older: 67.1 years $(p<0.0001)$ and had lower serum albumin values, $3.5 \mathrm{mg} / \mathrm{dl}(p<0.0001)$ compared with the rest of the groups. On the other hand, patients in the LS +F/G group had higher $P, 6.5 \mathrm{mg} / \mathrm{dl}, \mathrm{Hb} 10.1 \mathrm{~g} / \mathrm{dl}$ and iPTH compared with the rest of the groups, $\mathrm{P}<0.001, \mathrm{P}<0.0001$ y $\mathrm{P}<0.0001$, respectively. Regarding comorbidities, the $\mathrm{ES}+\mathrm{C}$ group had more patients with $\mathrm{DM}$ $37 \%(p<0.001), C D 51.2 \%(p<0.005)$ and PVD 20,5\% ( $p=0.029)$ compared with the rest of the groups. Patients in the LS + F/G group had more access to renal transplantation, $45.6 \%(p<0.0001)$ compared with the rest of the groups. Table 1 
Table 1

Patient's characteristics: full cohort

\begin{tabular}{|c|c|c|c|c|c|c|}
\hline Variable & $\begin{array}{l}\text { All patients } \\
n=503\end{array}$ & $\begin{array}{l}\mathrm{ES}+\mathrm{C}(> \\
7 \mathrm{ml} / \mathrm{min}) \\
\mathrm{n}=127\end{array}$ & $\begin{array}{l}\mathrm{ES}+\mathrm{F} / \mathrm{G}(> \\
7 \mathrm{ml} / \mathrm{min}) \\
\mathrm{n}=127\end{array}$ & $\begin{array}{l}\mathrm{LS}+\mathrm{C}(< \\
7 \mathrm{ml} / \mathrm{min}) \\
\mathrm{n}=113\end{array}$ & $\begin{array}{l}\mathrm{LS}+\mathrm{F} / \mathrm{G}(< \\
7 \mathrm{ml} / \mathrm{min}) \\
\mathrm{n}=136\end{array}$ & $\begin{array}{l}P \\
\text { value }\end{array}$ \\
\hline Age (years) & $61 \pm 17$ & $67.1 \pm 16$ & $58.2 \pm 16$ & $60.8 \pm 17$ & $58.1 \pm 16$ & $<0.0001$ \\
\hline Male Sex \% & 61.3 & 64.6 & 64.6 & 60.2 & 55.9 & 0.410 \\
\hline $\begin{array}{l}\text { Time on HD } \\
\text { (months) }\end{array}$ & $\begin{array}{l}30.9(13- \\
50)\end{array}$ & $20.3(6-40)$ & $33.2(17-47)$ & $28.6(7.7-51)$ & $37(18-68)$ & $\begin{array}{l}< \\
0.0001\end{array}$ \\
\hline \multicolumn{7}{|l|}{ Comorbidities } \\
\hline DM \% & 38.7 & 37 & 35.4 & 15 & 11.8 & $\begin{array}{l}< \\
0.0001\end{array}$ \\
\hline $\begin{array}{l}\text { Coronary Disease } \\
\%\end{array}$ & 52.1 & 51.2 & 41.7 & 32.7 & 30.1 & 0.005 \\
\hline PVD \% & 13.4 & 20.5 & 15 & 11.5 & 7.4 & 0.029 \\
\hline eGFR $\mathrm{ml} / \mathrm{min}$ & $7(5.3-9.5)$ & $9.7(8.3-12)$ & $8.9(7.9-12)$ & $5.4(4.3-6.1$ & $5.2(4.3-6.2)$ & $<0.0001$ \\
\hline $\begin{array}{l}\text { Fistula/prothesis } \\
\%\end{array}$ & 52.1 & & & & & \\
\hline \multicolumn{7}{|l|}{ Laboratory values } \\
\hline $\mathrm{Hb} \mathrm{g/dl}$ & $9.7 \pm 1.9$ & $9.6 \pm 1.7$ & $9.9 \pm 1.6$ & $9.1 \pm 1.6$ & $10.3 \pm 2.3$ & $\begin{array}{l}< \\
0.0001\end{array}$ \\
\hline Albumin g/dl & $3.7 \pm 0.5$ & $3.5 \pm 0.5$ & $3.7 \pm 0.6$ & $3.7 \pm 0.5$ & $3.9 \pm 0.4$ & $<0.0001$ \\
\hline Calcium mg/dl & $8.7 \pm 3.7$ & $8.7 \pm 0.9$ & $8.7 \pm 0.9$ & $8.2 \pm 1.2$ & $9.3 \pm 0.7$ & 0.194 \\
\hline $\begin{array}{l}\text { Phosphorous } \\
\mathrm{mg} / \mathrm{dl}\end{array}$ & $5.9 \pm 2$ & $5.1 \pm 1.7$ & $5.5 \pm 1.3$ & $6.4 \pm 2.1$ & $6.4 \pm 2.2$ & $<.0001$ \\
\hline iPTH pg/dl & $\begin{array}{l}311(154- \\
541)\end{array}$ & $208(108-400)$ & $260(155-529)$ & $369(197-633)$ & $423(222-580)$ & $<0.0001$ \\
\hline Urea mg/dl & $189 \pm 64$ & $167 \pm 62$ & $170 \pm 50$ & $214 \pm 68$ & $205 \pm 63$ & $<0.0001$ \\
\hline $\begin{array}{l}\text { Kidney Transplant } \\
\%\end{array}$ & 33.2 & 20.5 & 34.6 & 31 & 45.6 & $\begin{array}{l}< \\
0.0001\end{array}$ \\
\hline
\end{tabular}

\section{Propensity score matching of cohort}

We performed a logistic regression analysis being the indicator group CKD-EPI > or < of $7 \mathrm{ml} / \mathrm{min}$, to obtain PS for dialysis initiation timing, using the following covariates: age, sex, diabetes mellitus, levels of alb, $\mathrm{Hb}, \mathrm{Ca}, \mathrm{P}$ and VA. After propensity score matching, 180 patients (90 in each group) remained. After PS we divided this cohort again into four groups: ES +C, ES + F/G, LS + C and LS + F/G and almost all of the baseline parameters, including age, sex, DM, CD, PVD, Hb levels, alb, serum Ca, $\mathrm{P}, \mathrm{iPTH}$, and kidney transplant were comparable with no statistically significant differences. Table 2 
Table 2

Patient's characteristics after a propensity score matching

\begin{tabular}{|c|c|c|c|c|c|}
\hline \multirow[t]{2}{*}{ Variable } & $\begin{array}{l}\text { ES + C (> } \\
7 \mathrm{ml} / \mathrm{min})\end{array}$ & $\begin{array}{l}\mathrm{ES}+\mathrm{F} / \mathrm{G}(> \\
7 \mathrm{ml} / \mathrm{min})\end{array}$ & $\begin{array}{l}\mathrm{LS}+\mathrm{C}(< \\
7 \mathrm{ml} / \mathrm{min})\end{array}$ & $\begin{array}{l}\mathrm{LS}+\mathrm{F} / \mathrm{G}(< \\
7 \mathrm{ml} / \mathrm{min})\end{array}$ & $P$ value \\
\hline & $n=43$ & $n=47$ & $\mathrm{n}=41$ & $n=49$ & \\
\hline Age (years) & $62 \pm 19$ & $57 \pm 17$ & $60.5 \pm 16$ & $58.6 \pm 16$ & 0.428 \\
\hline Male Sex \% & 67 & 53.2 & 63.4 & 61.2 & 0.561 \\
\hline Time on HD (months) & $18.7(5-33)$ & $31(21-48)$ & $30.5(14-46)$ & $36(15-60)$ & 0.006 \\
\hline \multicolumn{6}{|l|}{ Comorbidities } \\
\hline DM \% & 20.9 & 15 & 19.5 & 18.4 & 0.896 \\
\hline Coronary Disease \% & 46.5 & 36.2 & 29.3 & 40.8 & 0.518 \\
\hline $\begin{array}{l}\text { Peripheral Vascular } \\
\text { Disease \% }\end{array}$ & 14 & 15 & 19.5 & 8.2 & 0.637 \\
\hline GFRe $\mathrm{ml} / \mathrm{min}$ & $9.2(8.2-11.5)$ & $8.3(7.6-9.8)$ & $5.9(4.3-6.6)$ & $5.3(4.5-6.3)$ & $\begin{array}{l}< \\
0.0001\end{array}$ \\
\hline \multicolumn{6}{|l|}{ Laboratory values } \\
\hline $\mathrm{Hb} \mathrm{g/dl}$ & $9.5 \pm 1.8$ & $9.8 \pm 1.7$ & $9.1 \pm 1.4$ & $10.2 \pm 3$ & 0.101 \\
\hline Albumin g/dl & $3.7 \pm 0.5$ & $3.8 \pm 0.6$ & $3.6 \pm 0.6$ & $3.9 \pm 0.4$ & 0.060 \\
\hline Calcium mg/dl & $8.7 \pm 0.8$ & $8.7 \pm 0.7$ & $8.3 \pm 1.2$ & $8.7 \pm 1.1$ & 0.317 \\
\hline Phosphorous mg/dl & $5.8 \pm 1.8$ & $5.9 \pm 1.4$ & $5.6 \pm 1.8$ & $6.0 \pm 1.6$ & 0.573 \\
\hline iPTH pg/dl & $241(78-411)$ & $287(163-540)$ & $338(171-520)$ & $426(246-547)$ & 0.118 \\
\hline Urea mg/dl & $181 \pm 62$ & $168 \pm 50$ & $189 \pm 63$ & $214 \pm 54$ & 0.001 \\
\hline Kidney Transplant \% & 32.6 & 34 & 27 & 38.8 & 0.693 \\
\hline
\end{tabular}

\section{Survival analysis}

A total of 469 patients exited during the observation period. The main reason was death 236 (46.9\%), kidney or kidneypancreas transplantation 167 (33.2\%), transfer to another dialysis unit 49 (9.8\%), and recovery of kidney function 17 (3.4\%). The main causes of death were: cardiovascular disease $41.7 \%$, infectious disease $26.9 \%$, and malignancies $11.4 \%$. Causes of death were not different between the four groups, neither for the full cohort $\left(\chi^{2} 12,035, p: 0.845\right)$ nor after PS matching ( $\chi^{2}$ $13,161, p$ : 0.782). Global mortality in the PS cohort was $46.7 \%(n=84)$

The survival time of the whole cohort was 30.9 months (13-50), survival time for $E S+C, E S+F / G, L S+C$, and LS + F/G was 20.3(6-40), 33.2(17-47), 28.6(7.7-51), 37(18-68) respectively. Before PS matching, the ES + $C$ group had a worse survival rate: Log-rank test: $48.510(P<0.0001)$ compared with the other groups, while the $L S+F / G$ group had the best survival rate. Figure 1

After matching, the propensity score-adjusted patient cohort confirmed that patients beginning HD earlier with a catheter as vascular access had higher mortality. Log-rank test: $11.338(P<0.010)$. Figure 2

We made univariate and multivariate Cox regression models to establish independent predictors of mortality. Within the entire cohort, univariate Cox analysis showed that starting HD with a CKD-EPI $<7 \mathrm{ml} / \mathrm{min}$ and a catheter was associated with a 339 $\%$ increased risk of all-cause mortality (OR 3.392; 95\% Cl 2.34-4.90); $\mathrm{P}<0.0001$. Multivariate Cox regression analysis revealed 
that even though other variables were predictors for mortality, such as age, DM, PVD, and albumin, ES + C persisted as an independent predictor of mortality (OR 1.625; $95 \% \mathrm{Cl} 1.05-2.50) ; \mathrm{P}<0.027$. Table 3

Table 3. Univariate and multivariate Cox regression analysis for all-cause mortality in the whole study population Model 1 Univariate Multivariate

\begin{tabular}{|lcccccccc|}
\hline Variable & Exp b & $\mathbf{9 5} \% \mathrm{Cl}$ & & $\boldsymbol{P}$ & Exp b & $\mathbf{9 5 \%} \mathrm{Cl}$ & $\boldsymbol{P}$ \\
& & Lower & Upper & & & Lower & Upper & \\
\hline eGFR+VA: Ref LS+F/G & & & & & & & & \\
\hline ES+C & 3.392 & 2.344 & 4.907 & $\mathbf{0 . 0 0 0}$ & 1.625 & 1.057 & 2.500 & $\mathbf{0 . 0 2 7}$ \\
\hline ES+F/G & 1.664 & 1.136 & 2.430 & $\mathbf{0 . 0 0 9}$ & 1.487 & 0.975 & 2.266 & 0.065 \\
\hline LS+C & 1.618 & 1.084 & 2.414 & $\mathbf{0 . 0 1 8}$ & 1.095 & 0.702 & 1.711 & 0.688 \\
\hline Age & 1.056 & 1.056 & 1.067 & $\mathbf{0 . 0 0 0}$ & 1.052 & 1.040 & 1.065 & $\mathbf{0 . 0 0 0 1}$ \\
\hline DM & 1.971 & 1.493 & 2.602 & $\mathbf{0 . 0 0 0}$ & 1.529 & 1.129 & 2.071 & $\mathbf{0 . 0 0 6}$ \\
\hline Coronary Disease & 1.556 & 1.199 & 2.019 & $\mathbf{0 . 0 0 1}$ & 0.902 & 0.674 & 1.206 & 0.486 \\
\hline Peripheral vascular Disease & 2.581 & 1.902 & 3.502 & $\mathbf{0 . 0 0 0}$ & 1.899 & 1.367 & 2.638 & $\mathbf{0 . 0 0 0 1}$ \\
\hline Urea & 0.997 & 0.995 & 0.999 & $\mathbf{0 . 0 0 7}$ & 1.000 & 0.998 & 1.003 & 0.915 \\
\hline Phosphorus & 0.890 & 0.830 & 0.954 & $\mathbf{0 . 0 0 1}$ & 1.021 & 0.940 & 1.110 & 0.616 \\
\hline Albumin & 0.587 & 0.481 & 0.717 & $\mathbf{0 . 0 0 0}$ & 0.611 & 0.479 & 0.779 & $\mathbf{0 . 0 0 0 1}$ \\
\hline
\end{tabular}

Abbreviations: eGFR (estimated glomerular filtrate rate), VA (vascular access), LS+F/G (late start with fistula or graft), ES+C (early start with catheter), ES+F/G (early start with fistula or graft), LS+C (late start with catheter), DM (diabetes mellitus).

\section{eGFR, albumin and malnutrition.}

To exclude a possible contribution of malnutrition to mortality in patients with high eGFR and low serum creatinine, we first performed a correlation between serum creatinine and albumin. We found that correlation was poor ( $r$ Pearson 0.14$)$ although $p$-value was significant $(p<0.001)$. Figure 3 Therefore, we then excluded from the analysis 150 patients with albumin less than a $3.5 \mathrm{~g} / \mathrm{dl}$. We recalculated Kaplan-Meier's survival curves for the four groups. ES + C group was still associated with higher mortality Log-rank test:36.793 ( $\mathrm{p}<0.0001)$. Figure 4. In Table 4, we performed a multivariate analysis with the significant variables of the univariate analysis such as age, PVD, P, eGFR and the four groups. Taking LS +F/G as the reference group, ES + F/G had significantly higher mortality (OR: $3.01 \mathrm{Cl}: 1.17-7.72) \mathrm{p}<0.02$. ES + C group had a nonsignificant tendency towards higher mortality (OR: $2.22 \mathrm{Cl}$ : 0.90-5.71) p: 0.09 (Model 1). We then segregated eGFR from the vascular access in the multivariate analysis, and eGFR remains as an independent predictor of mortality $(\mathrm{OR}: 1.098, \mathrm{Cl} 1.021-$ 1.182) $p<0.01$. (Model 2). Table 4 
Table 4

Univariate and multivariate Cox regression analysis for all-cause mortality in patients with albumin $>3.5 \mathrm{~g} / \mathrm{dl}$ Univariate Multivariate model 1 Multivariate model 2

\begin{tabular}{|c|c|c|c|c|c|c|c|c|c|c|c|c|}
\hline \multirow{2}{*}{$\begin{array}{l}\text { Variable } \\
\text { Age }\end{array}$} & \multirow{2}{*}{$\begin{array}{l}\operatorname{Exp} \beta \\
1.051\end{array}$} & \multicolumn{2}{|c|}{$\begin{array}{l}95 \% \mathrm{Cl} \\
\text { lower upper }\end{array}$} & \multirow{2}{*}{$\begin{array}{l}P \\
0.000\end{array}$} & \multirow{2}{*}{$\begin{array}{l}\operatorname{Exp} \beta \\
1.048\end{array}$} & \multicolumn{2}{|c|}{$\begin{array}{l}95 \% \mathrm{Cl} \\
\text { lower upper }\end{array}$} & \multirow{2}{*}{$\begin{array}{l}P \\
0.000\end{array}$} & \multirow{2}{*}{$\begin{array}{l}\operatorname{Exp} \beta \\
1.047\end{array}$} & \multicolumn{2}{|c|}{$\begin{array}{l}95 \% \mathrm{Cl} \\
\text { lower upper }\end{array}$} & \multirow{2}{*}{$\begin{array}{l}P \\
0.0001\end{array}$} \\
\hline & & 1.030 & 1.072 & & & 1.025 & 1.071 & & & 1.025 & 1.070 & \\
\hline PVD & 3.519 & 1.770 & 7.001 & 0.000 & 2.795 & 1.363 & 5.731 & 0.005 & 3.061 & 1523 & 6151 & 0.002 \\
\hline Phosphorus & 0.815 & 0.717 & 0.926 & 0.002 & & & & & & & & \\
\hline eGFR & 1.091 & 1.027 & 1.158 & 0.005 & & & & & 1.098 & 1.021 & 1.182 & 0.012 \\
\hline \multicolumn{13}{|l|}{$\begin{array}{l}\text { LS + F/G: } \\
\text { ref. group }\end{array}$} \\
\hline$E S+C$ & 3.360 & 1.545 & 7.307 & 0.002 & 2.228 & 0.900 & 5.718 & 0.090 & & & & \\
\hline$E S+F / G$ & 2.410 & 1.065 & 5.454 & 0.035 & 3.013 & 1.176 & 7.720 & 0.022 & & & & \\
\hline$L S+C$ & 1.541 & 0.650 & 3.663 & 0.327 & 1.275 & 0.466 & 3.490 & 0.636 & & & & \\
\hline
\end{tabular}

\section{Discussion}

We have evaluated all-cause mortality in four groups of patients that entered hemodialysis according to renal function and type of vascular access used of an incident cohort of patients initiating dialysis in our dialysis unit. In the full cohort analysis, the ES + C group had higher mortality. This group of patients were also older, they had more co-morbid conditions such as DM, $C D$, and PVD, hypoalbuminemia and lower phosphorus values compared with the rest of the groups. Therefore, patients with higher comorbidities might have been those who entered dialysis earlier and with a catheter as they had more complications as a cause or consequence of ESRD. We decided to calculate PS, which allowed us to match groups in terms of age, comorbid conditions and most laboratory values. It was interesting to find that after matching ES + C group was still associated with higher mortality. Previously most studies reporting the advantage of early dialysis initiation were of a retrospective observational design, and thus the adjustments made for demographic factors and co-morbid conditions were insufficient [21-23]. Lead-time bias favoring ES dialysis should be considered in these studies. This is, the statistical misconception that patients lived longer simply because they started dialysis earlier [7]. During the last decades, patients were admitted to dialysis earlier. It was based on the assumption that a decrease in uremic toxins and a reduction in the complications associated with CKD could increase patient survival [24]. However, Clark et al. evaluated 25910 patients and showed that those starting dialysis earlier (GFR $>10.5 \mathrm{~mL} / \mathrm{min}$ per $1.73 \mathrm{~m}^{2}$ ) had an increased risk of death [25]. Others studies also demonstrated that starting dialysis early was not associated with an improvement in survival or in clinical outcomes [26-29], on the contrary it can be related with several complications related to dialysis treatment as malnutrition, loss of residual diuresis, anemia and cardiovascular disorders, among others [30-32]. On the other hand, many studies found that older patients, patients with DM, and patients with higher reported co-morbid conditions and low body mass index-initiated dialysis early [7]. Although, recently, Rosansky and Clark reported that the trend towards an early dialysis start might be reversing, starting in 2009 [10]. Many things might relate to this international change of trend, including no benefit from early start in the IDEAL (Initiation of Dialysis Early or Late) randomized controlled trial. Cooper et al, studied 828 adults patients with progressive CKD and a GFR between 10.0 and $15.0 \mathrm{ml}$ per minute per $1.73 \mathrm{~m}^{2}$ who were planned to initiate dialysis when the estimated GFR was 10.0 to $14.0 \mathrm{ml}$ per minute (early start) or when the estimated GFR was 5.0 to $7.0 \mathrm{ml}$ per minute (late start). They found that programed early initiation of dialysis in patients with CKD stage 5 was not associated with an improvement in survival or clinical outcomes: treatment-associated complications, cardiovascular events, infections and quality of life [14,33]. There is also evidence of possible detriment of early start of dialysis in a 1996-2008 United States cohort of patients under age 65 with low comorbidity [6]. For the United States population aged $\geq 67$ years newly starting dialysis, Crews et al. reported that patients 
with an early dialysis start had comorbidity-adjusted greater mortality and hospitalizations than patients who started at a lower estimated GFR (eGFR) [34]. Crew et al. in a retrospective cohort study, enrolled 652 CKD patients who had at least one face-to-face outpatient encounter with a health care provider prior to the beginning of dialysis and evaluated the clinical outcomes after eGFR reached approximately $20 \mathrm{ml} / \mathrm{min} / 1.73 \mathrm{~m} 2$, to reduce the effect of the lead-time and survival bias. This study showed no difference in survival whether patients started dialysis early or late [35]. On the other hand, previous studies in incident HD patients have shown that catheter use is associated with an increased mortality rate for any razon. Lorenzo et al. published that in 538 patients a nonprogrammed dialysis initiation (late referral) and the use of temporary catheters were independently associated with significant mortality, particularly at 1 year [17]. Similarly, Pastan et al. showed that in 7497 patients the use of a catheter whether the tunneled or not was associated with a substantial mortality compared with AV fistula (OR 1.4, $\mathrm{Cl} 1.1-1.9)$ or PTFE graft (OR 1.3, $\mathrm{Cl} 1.1-1.6)$. This increased mortality was observed during dialysis and longterm follow-up [18]. Catheter or access site-related bloodstream infections are increased in patients undergoing dialysis [36]. These factors may contribute to the poor survival and adverse clinical outcomes of patients with early dialysis beginning [7].

To our knowledge, no studies are using these two variables (eGFR and vascular access at entry) simultaneously in four groups to assess mortality. Although our study is retrospective, we were able to show that initiating dialysis with an eGFR greater than $7 \mathrm{ml} / \mathrm{min}$ and a catheter was associated with higher mortality even after PS matching.

To exclude a possible contribution of malnutrition to mortality in patients with high eGFR and low serum creatinine, we recalculated survival after excluding patients with albumin lower than $3.5 \mathrm{mg} / \mathrm{dl}$. Even in this scenario, those initiating dialysis with an eGFR $>7 \mathrm{ml} / \mathrm{min}$ and a catheter had higher mortality. Nevertheless, when we split these two variables (eGFR and vascular access at entry) in multivariate analysis, eGFR remains an independent predictor of mortality (OR:1.098, CI 1.0211.182) $p<0.01$.

This study has several limitations. This is an observational retrospective single-center cohort study with a relatively low number of patients starting at the time of dialysis initiation. Therefore, we cannot exclude lead-time and survivor bias. Also, parameters like PCR to assess inflammation status were not included.

We used CKD-EPI to estimate GFR. This formula could have overestimated GFR in malnourished subjects. We have tried to surpass this problem by excluding patients with low serum albumin. Although we know albumin can be affected by conditions other than malnutrition, results were consistent.

Our results conflict with the knowledge that a lower GFR equals a worse prognosis. Although it may seem that our findings are not consistent with others, either prospective randomized studies like IDEAL which showed no differences between ES vs. LS, or observational studies showing higher mortality in the ES group but associated with higher age and comorbidities, they are consistent with those same studies showing no benefit or even detrimental effect of early initiation of dialysis and it is unique in the inclusion of the vascular access used at the same time. Also, propensity score analysis allowed us to match the cohorts, including age, comorbidities, and laboratory values (albumin, hemoglobin, phosphorus) that became similar between the early and late-start groups. Based on or in view of the results of recent studies, the new guidelines recommend delaying dialysis and addressing significant clinical signs or symptoms rather than starting dialysis treatment alone based on GFR values [15].

\section{Conclusions}

In this retrospective cohort study, patients starting dialysis early and with a catheter were associated with a higher mortality rate than those starting late. This association persisted after propensity score matching. Our results and others showing no benefit or even detrimental effect of early initiation of dialysis are in line with newer guidelines recommending individualized clinical assessment rather initiation based on eGFR values.

\section{Declarations}

\section{Ethics approval and consent to participate:}

Page $9 / 15$ 
We confirm that all methods were performed in accordance with Declarations of Helsinki ethical principles.

Cemic's ethics committee approved this project, exempting it from requesting an informed consent from patients due to a retrospective nature of this study.

Statement from Comité de Ética del Centro de Educación Médica e Investigaciones Clínicas (CEMIC) is uploaded as a related file.

Consent for publication: 'Not applicable'

Availability of data and material:

The datasets used and analyzed during the current study is available from the corresponding author on reasonable request.

\section{Competing interests:}

The authors have not competing of interest to declare

\section{Funding:}

There was not funding for this study

\section{Authors Contributions:}

All authors contributed with: design of the work, statistics analysis, interpretation of data, drafting the work, final approval of the version to be published. Agreement in all aspects of the work in ensuring questions related to the accuracy of any part of the paper. Everything was appropriately investigated and resolved for the authors.

\section{Acknowledgements: No}

\section{References}

1. Zhang, QL., Rothenbacher, D. Prevalence of chronic kidney disease in population-based studies: Systematic review. BMC Public Health https://doi.org/10.1186/1471-2458-8-117

2. Registro Argentino de Diálisis Crónica 2019. Informe 2019. Instituto Nacional Central Único Coordinador de Ablación e Implante (INCUCAI), sociedad Argentina de Nefrología. Available from: https://san.org.ar/docs/Registro_Argentino_de_Dialisis_Cronica_2019\%20INFORME\%202020.pdf

3. Chan KE, Maddux FW, Tolkoff-Rubin N, Karumanchi SA, Thadhani R, Hakim RM. Early Outcomes among Those Initiating Chronic Dialysis in the United States. Clin J Am Soc Nephrol. 2011; 6:2642-2649

4. Matthew B. Rivara, MD and Rajnish Mehrotra, MD, MS. Timing of Dialysis Initiation - What Has Changed Since IDEAL? Semin Nephrol. 2017 March; 37(2): 181-193.

5. Carson RC, Juszczak M, Davenport A, Burns A. Is maximum conservative management an equivalent treatment option to dialysis for elderly patients with significant co-morbid disease? Clin J Am Soc Nephrol. 2009 Oct;4(10):1611-9.

6. Chandna SM, Da Silva-Gane M, Marshall C, Warwicker P, Greenwood RN, Farrington K. Survival of elderly patients with stage 5 CKD: comparison of conservative management and renal replacement therapy. Nephrol Dial Transplant. 2011 May;26(5):1608-14.

7. Lee J, An JN, Hwang JH, Kim Y-L, Kang S-W, Yang CW, et al. Effect of dialysis initiation timing on clinical outcomes: a propensity-matched analysis of a prospective cohort study in Korea. PloS One. 2014; 9:e105532.

8. Rosansky SJ, Clark WF. Has the yearly increase in the renal replacement therapy population ended? J Am Soc Nephrol. 2013;24(9):1367-1370. 
9. Susantitaphong P, Altamimi S, Ashkar M, Balk EM, Stel VS, Wright S, Jaber BL. GFR at initiation of dialysis and mortality in CKD: a meta-analysis. Am J Kidney Dis. 2012 Jun;59(6):829-40.

10. Rosansky SJ, Clark WF, Eggers P, Glassock RJ. Initiation of dialysis at higher GFRs: is the apparent rising tide of early dialysis harmful or helpful? Kidney Int. 2009 Aug;76(3):257-61.

11. Mehrotra R, Rivara M, Himmelfarb J. Initiation of dialysis should be timely: neither early nor late. Semin Dial. 2013; 26:644-649.

12. Churchill DN. An evidence-based approach to earlier initiation of dialysis. Am J Kidney Dis Off J Natl Kidney Found. 1997; 30:899-906.

13. Grootendorst DC, Michels WM, Richardson JD, Jager KJ, Boeschoten EW, Dekker FW, et al. The MDRD formula does not reflect GFR in ESRD patients. Nephrol Dial Transplant. 2011; 26:1932-1937

14. Cooper BA, Branley P, Bulfone L, Collins JF, Craig JC, Fraenkel MB, Harris A, Johnson DW, Kesselhut J, Li JJ, Luxton G, Pilmore A, Tiller DJ, Harris DC, Pollock CA, IDEAL Study: A randomized, controlled trial of early versus late initiation of dialysis. N Engl J Med. 2010; 363: 609-619.

15. Crews DC, Scialla JJ, Liu J, Guo H, Bandeen-Roche K, Ephraim PL, et al. Predialysis Health, Dialysis Timing, and Outcomes among Older United States Adults. J Am Soc Nephrol. 2014; 25:370-379.

16. Stack, AG: Impact of Timing of nephrology referral and pre-ESRD care on mortality risk among new ESRD patients in the United States. Am J Kidney Dis. 2003; 41:310-8.

17. Lorenzo V, Martin M, Rufino M, Hernandez D, Torres A, Ayus JC. Predialysis nephrologic care and a functioning arteriovenous fistula at entry are associated with better survival in incident hemodialysis patients: an observational cohort study. Am J Kidney Dis. 2004; 43:999-1007.

18. Pastan S, Soucie JM, McClellan W, et al. Vascular access and increased risk of death among hemodialysis patients. Kidney International. August 2002, Volume 62, Issue 2, Pages 620-626.

19. Levey AS, Stevens LA, Schmid $\mathrm{CH}$, et al. A new equation to estimate glomerular filtration rate [published correction appears in Ann Intern Med. 2011 Sep 20;155(6):408]. Ann Intern Med. 2009;150(9):604-612.

20. Cooper BA, Aslani A, Ryan M, Ibels LS, Pollock CA. Nutritional state correlates with renal function at the start of dialysis. Perit Dial Int. 2003 May-Jun;23(3):291-5.

21. Tang SC, Ho YW, Tang AW, Cheng YY, Chiu FH, et al. Delaying initiation of dialysis till symptomatic uraemia-is it too late? Nephrol Dial Transplant. 2007; 22: 1926-1932.

22. Traynor JP, Simpson K, Geddes CC, Deighan CJ, Fox JG. Early initiation of dialysis fails to prolong survival in patients with end-stage renal failure. J Am Soc Nephrol. 2002; 13: 2125-2132.

23. Hwang SJ, Yang WC, Lin MY, Mau LW, Chen HC. Impact of the clinical conditions at dialysis initiation on mortality in incident haemodialysis patients: a national cohort study in Taiwan. Nephrol Dial Transplant.2010; 25: 2616-2624.

24. Collins J, Cooper B, Branley P, Bulfone L, Craig J, et al. Outcomes of patients with planned initiation of hemodialysis in the IDEAL trial. Contrib Nephrol. 2011; 171: 1-9.

25. Clark WF, Na Y, Rosansky SJ, Sontrop JM, Macnab JJ, Glassock RJ, Eggers PW, Jackson K, Moist L. Association between estimated glomerular filtration rate at initiation of dialysis and mortality. CMAJ. 2011 Jan 11;183(1):47-53.

26. Rosansky SJ, Eggers P, Jackson K, Glassock R, Clark WF. Early start of hemodialysis may be harmful. Arch Intern Med. 2011; 171: 396-403.

27. Lassalle M, Labeeuw M, Frimat L, Villar E, Joyeux V, et al. Age and comorbidity may explain the paradoxical association of an early dialysis start with poor survival. Kidney Int. 2010; 77: 700-707.

28. Sawhney S, Djurdjev O, Simpson K, Macleod A, Levin A. Survival and dialysis initiation: comparing British Columbia and Scotland registries. Nephrol Dial Transplant. 2009; 24: 3186-3192

29. Wright S, Klausner D, Baird B, Williams ME, Steinman T, et al. Timing of dialysis initiation and survival in ESRD. Clin J Am Soc Nephrol. 2010; 5: 1828-1835. 
30. Jansen MA, Hart AA, Korevaar JC, Dekker FW, Boeschoten EW, et al. Predictors of the rate of decline of residual renal function in incident dialysis patients. Kidney Int. 2002; 62: 1046-1053.

31. Mehrotra R, Duong U, Jiwakanon S, Kovesdy CP, Moran J, et al. Serum albumin as a predictor of mortality in peritoneal dialysis: comparisons with hemodialysis. Am J Kidney Dis. 201; 58: 418-428.

32. Fouque D, Kalantar-Zadeh K, Kopple J, Cano N, Chauveau P, et al. A proposed nomenclature and diagnostic criteria for protein-energy wasting in acute and chronic kidney disease. Kidney Int. 2008; 73: 391-398.

33. Johnson DW, Wong MG, Cooper BA, Branley P, Bulfone L, et al. Effect of Timing of dialysis commencement on clinical outcomes of patients with planned initiation of peritoneal dialysis in the IDEAL trial. Perit Dial Int. 2012; 32:595-604.

34. Crews, D. C., Scialla, J. J., Liu, J., Guo, H., Bandeen-Roche, K., Ephraim, P. L., Jaar, B. G., Sozio, S. M., Miskulin, D. C., Tangri, N., Shafi, T., Meyer, K. B., Wu, A. W., Powe, N. R., Boulware, L. E., \& Developing Evidence to Inform Decisions about Effectiveness (DEcIDE) Patient Outcomes in End Stage Renal Disease Study Investigators. Predialysis health, dialysis timing, and outcomes among older United States adults. Journal of the American Society of Nephrology: JASN, 2014; 25(2), 370-379.

35. Crews DC, Scialla JJ, Boulware LE, Navaneethan SD, Nally JV Jr, et al. Comparative effectiveness of early versus conventional Timing of dialysis initiation in advanced CKD. Am J Kidney Dis. 2014; 63: 806-815.

36. Nguyen DB, Lessa FC, Belflower R, Mu Y, Wise M, et al. Invasive methicillin-resistant Staphylococcus aureus infections among patients on chronic dialysis in the United States, 2005-2011. Clin Infect Dis. 2013; 57: 1393-1400.

\section{Figures}

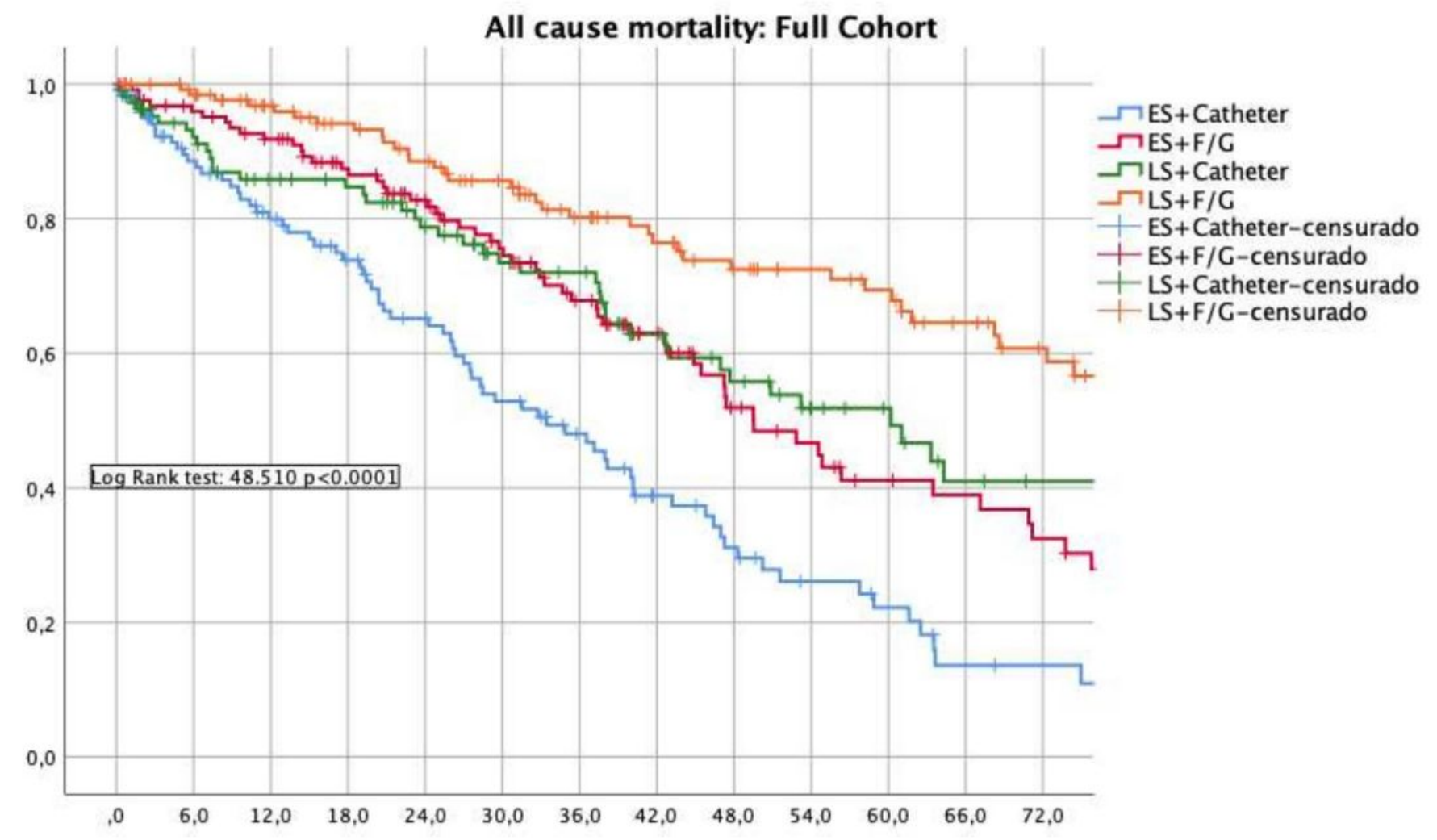

Time on hemodiálisis (months)

Figure 1

All-cause mortality: Full Cohort 


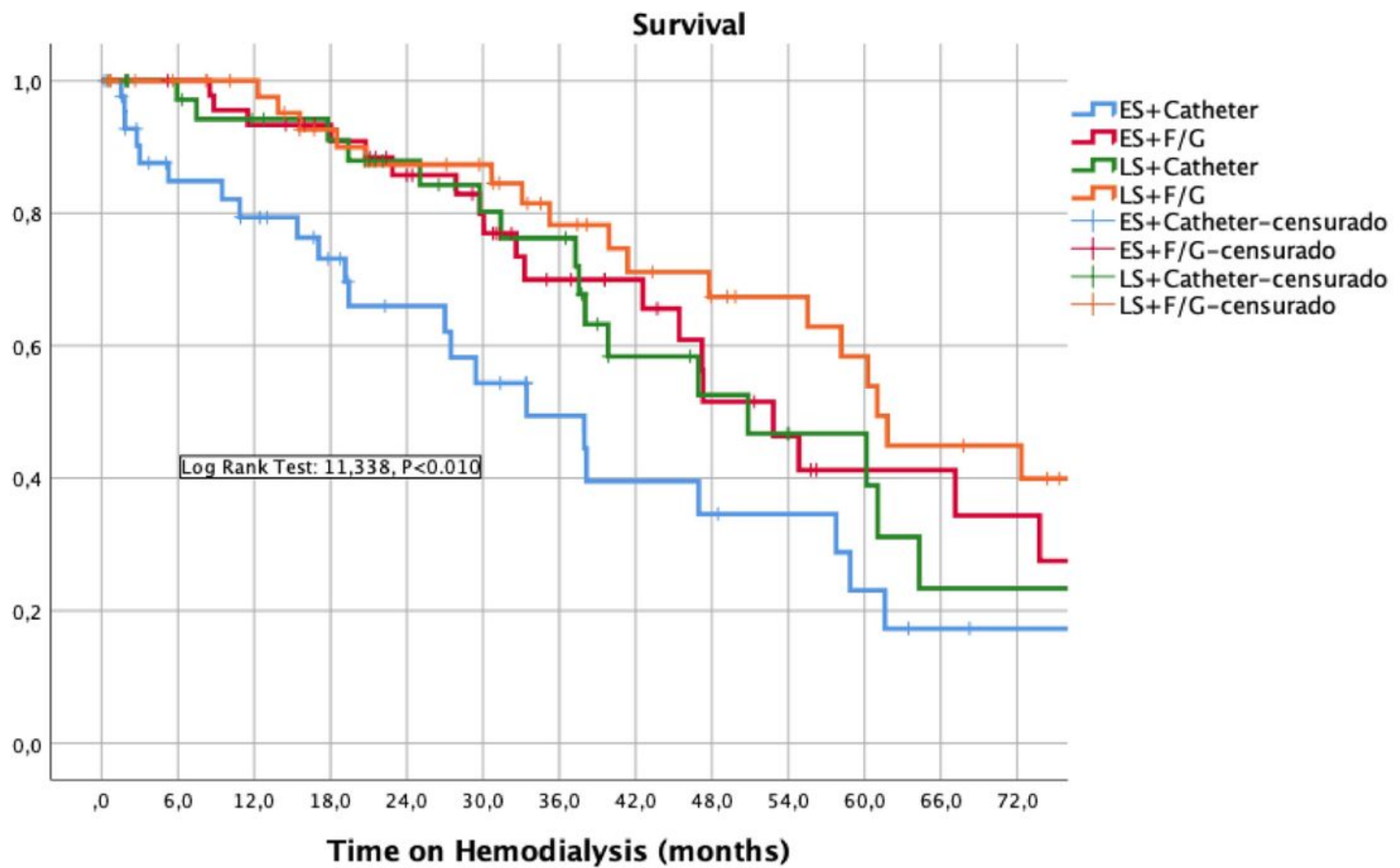

Figure 2

All-cause mortality: Propensity score cohort 


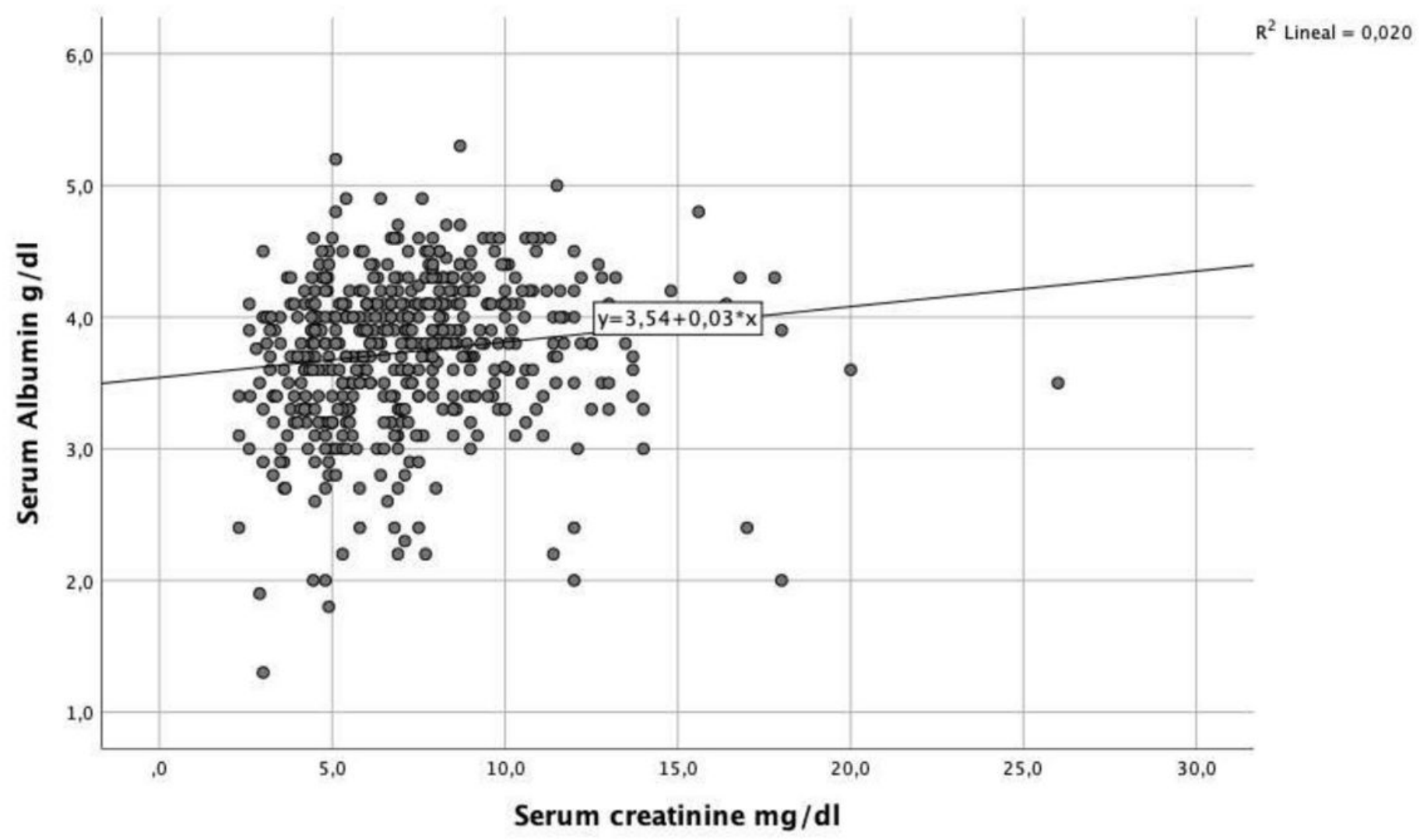

Figure 3

Correlation between serum creatinine and albumin 


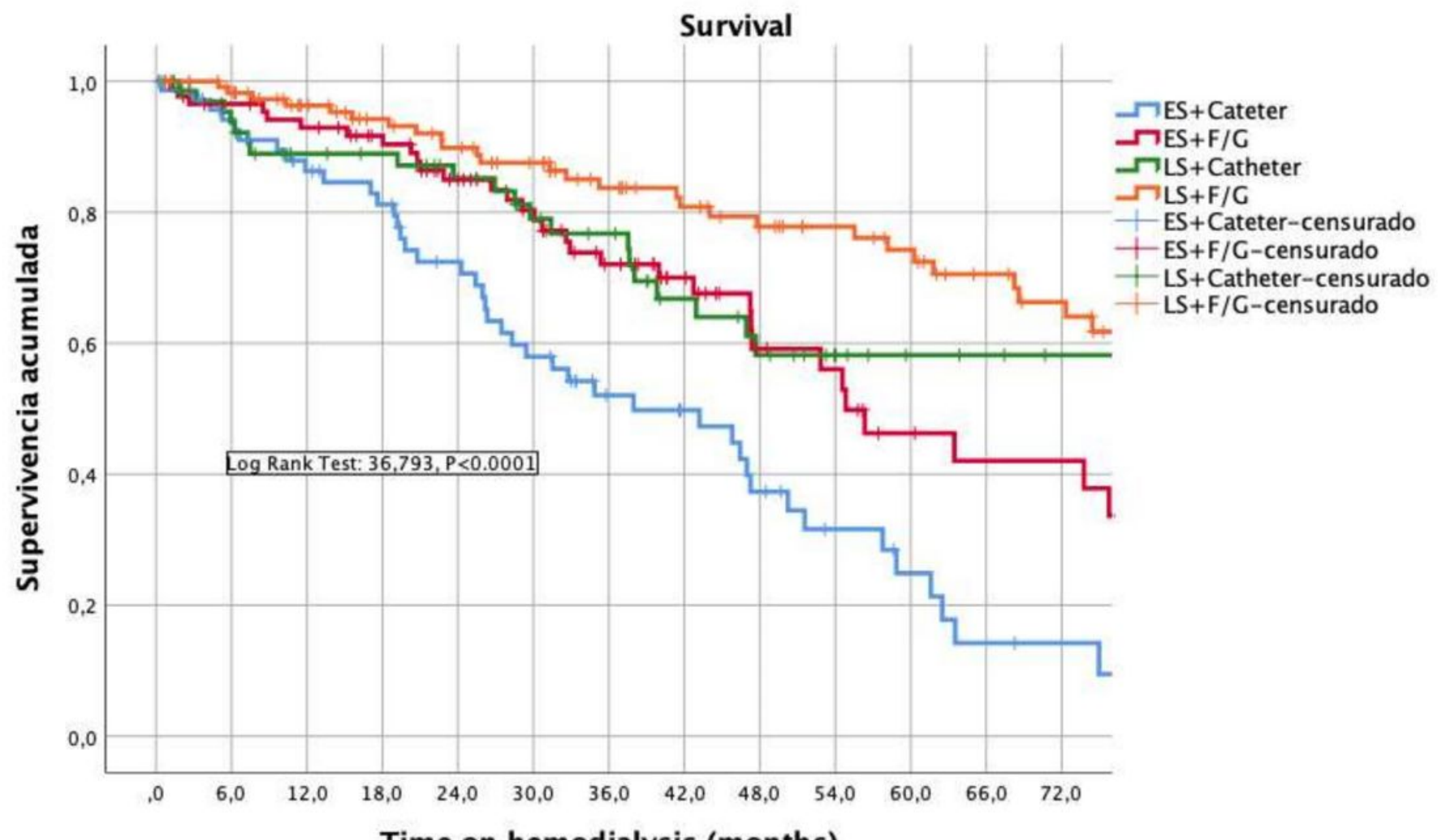

Time on hemodialysis (months)

Figure 4

All-cause mortality excluding patients with albumin $<3.5 \mathrm{~g} / \mathrm{dl}$ 